\title{
Self-healing capability of cementitious composites incorporating different supplementary cementitious materials
}

\author{
Mustafa Sahmaran $^{\mathrm{a}, *}$, Gurkan Yildirim ${ }^{\mathrm{a}}$, Tahir K. Erdem ${ }^{\mathrm{b}}$ \\ a Department of Civil Engineering, Gaziantep University, Gaziantep, Turkey \\ ${ }^{\mathrm{b}}$ Department of Civil Engineering, İzmir Institute of Technology, Izmir, Turkey
}

\section{A R T I C L E I N F O}

\section{Article history:}

Received 30 November 2011

Received in revised form 27 July 2012

Accepted 19 August 2012

Available online 29 August 2012

\section{Keywords:}

Self-healing

Engineered Cementitious Composites (ECCs)

Supplementary cementitious material (SCM)

Exposure conditions

\begin{abstract}
A B S T R A C T
The presence of deleterious substances and their transport are among the most important factors controlling the durability of cementitious composites. The present paper studies the relationship among the applied mechanical deterioration in terms of splitting tensile deformation, curing conditions and chloride ion permeability of Engineered Cementitious Composites (ECCs) that contain different supplementary cementitious materials (SCMs). Three SCMs, representing a wide range of compositions, were used in the study. The splitting tensile deformations are introduced to generate microcracks in ECC specimens, where cylindrical specimens were pre-loaded to different deformation levels. After that, the mechanically pre-cracked and pristine ECC specimens were exposed to three different curing conditions (continuous wet, continuous air, and freeze-thaw cycle) for up to 2 months. Rapid chloride permeability test (RCPT), microscopic observation and microstructural analysis were used to assess the rate and extent of selfhealing. Test results indicate that the SCM type greatly affects the self-healing capability of cementitious composites as measured by chloride ion permeability. Although ECC samples with fly ash have more unhydrated cementitious materials, and therefore, expectedly, a higher capacity for self-healing, more evident self-healing product was observed from the ECC mixture incorporating slag. Therefore, in addition to the crack width distribution and curing condition, the reaction products associated with SCMs have a great impact on the self-healing capability of cementitious composites.
\end{abstract}

(ㄷ) 2012 Elsevier Ltd. All rights reserved.

\section{Introduction}

Lack of durability has been recognized as a major concern in construction practices for the past decades. One of the most severe concerns is the sharp decrease in durability associated with concrete cracking that may originate from external effects, harsh environment, poor workmanship, or due to concrete itself in the case of restraining conditions [1]. Since the low durability of many concrete structures can be associated with the brittle nature of concrete, the development of ductile concretes is highly desirable. Along this line, Engineered Cementitious Composites (ECCs) have been developed over the past two decades.

ECC is a special type of high performance fiber-reinforced cementitious composite featuring high ductility and damage tolerance under mechanical loading, including tensile and shear loadings [2,3]. By employing micromechanics-based material optimization, tensile strain capacity in excess of $3 \%$ under uniaxial tensile loading can be attained with only $2 \%$ fiber content, by volume $[2,4,5]$. Strain-hardening behavior, which is one of the mate-

\footnotetext{
* Corresponding author. Tel.: +90 342317 2410; fax: +90 3423601107.

E-mail address: sahmaran@gantep.edu.tr (M. Sahmaran).
}

rial characteristics of ECC, is associated with the multiple narrow crack phenomenon of the brittle matrix. Narrow crack width, which is generally less than $100 \mu \mathrm{m}$, self-controlled and free of reinforcement is an intrinsic characteristic of ECC. The narrow crack width is a significant parameter for self-healing.

Experimental research and practical experience have demonstrated that cracks in concrete have the potential to seal themselves. Self-healing is generally attributed to the hydration of previously unhydrated cementitious material, calcite formation, expansion of the concrete in the crack flanks, crystallization, closing of cracks by solid matter in the water and closing of the cracks by spalling of loose concrete particles resulting from cracking [6]. Self-healing of cracks should be taken into account when specifying tolerable crack widths. Jacobsen et al. [6], Reinhardt and Joss [7], Şahmaran and Yaman [8], Edvardsen [9], Aldea et al. [10] and Clear [11] have proposed the maximum crack widths as 5$10 \mu \mathrm{m}, 100 \mu \mathrm{m}, 200 \mu \mathrm{m}, 205 \mu \mathrm{m}$ and $300 \mu \mathrm{m}$, respectively, in order for a crack to seal itself completely. In all, it is pointed out that the most serious challenge for complete healing of a crack is tolerable crack width. Because conventional concrete has the tendency to deform in a brittle manner under mechanical loading, the attainment of such small crack widths is a major concern. Since the crack 
width was identified as a key factor in the self-healing of concrete materials, tight crack widths in ECC are likely to promote self-healing behavior.

Recently, usage of supplementary cementitious materials (SCMs) as a component of ECC has become usual [12-14]. SCMs are used for several reasons through the production of ECC. The absence of coarse aggregates in ECC results in higher Portland cement content. Therefore, partial replacement of Portland cement with SCMs can lower the material cost, reduce environmental burden and enhance greenness, since the production of these materials needs less energy and causes less carbon dioxide emission than that of cement.

While knowledge of the effect of SCMs on the mechanical and durability properties of cementitious composites is available, the effects of SCM types on self-healing capability of ECC are limited in literature, especially in the case of exposure to various environmental conditions and pre-loading deformation levels. The present work investigates the influences of different mineral admixtures on the self-healing capabilities of ECC under various environmental exposure conditions. For this purpose, ECC mixtures, which contain different mineral admixture types, were produced and exposed to the different splitting tensile pre-loading deformation levels for the disturbance of specimens. Three typical SCMs (i.e., a low-calcium fly ash, a high-calcium fly ash and a slag) were used, representing a wide range of chemical compositions, from highly pozzolanic to almost cementitious. The specimens were then exposed to three different environmental conditions (continuous air (CA), continuous wet (CW), and freeze/thaw cycle $(\mathrm{F} / \mathrm{T})$ ) to assess the self-healing capability of ECC mixtures incorporating different SCMs by measuring the chloride ion permeability of the ECC according to the ASTM C1202 [15]. Microstructural changes within the cracks were also analyzed using scanning electron microscopy (SEM) and video microscope. X-ray diffraction (XRD) analyses are also carried out in order to confirm the composition of chemical products necessary for self-healing.

\section{Experimental program}

\subsection{Materials and mixture proportions}

An experimental program was designed to investigate the selfhealing capability of ECC mixtures based on mineral admixture type, mechanical pre-loading deformation level and curing regime. For this purpose, three different ECC mixtures were prepared: F_ECC, C_ECC and S_ECC with Class-F fly ash, Class-C fly ash and slag, respectively. During the production process, a standard mortar mixer was used to produce specimens with water to cementitious material ratio $(\mathrm{W} / \mathrm{CM})$ of 0.27 and mineral admixture to Portland cement (FA/PC or S/PC) ratio of 2.2. The proportions of three mixtures are presented in Table 1.

The ingredients used in the ECC mixtures were CEM I 42.5 type ordinary Portland cement (PC), Class-F fly ash (F), Class-C fly ash (C), ground granulated blast furnace slag (S), sand, polyvinyl-alcohol fibers (PVA), water and high range water reducing admixture (HRWRA). The physical and chemical characteristics of PC and SCMs are presented in Table 2. Fig. 1 shows their particle size distributions. In line with micromechanical design of ECC, it is
Table 2

Chemical and physical properties of Portland cement, fly ashes and slag.

\begin{tabular}{lrrrr}
\hline Chemical composition & \multicolumn{1}{c}{$\mathrm{PC}$} & \multicolumn{1}{c}{$\mathrm{F}$} & \multicolumn{1}{c}{$\mathrm{C}$} & \multicolumn{1}{l}{$\mathrm{S}$} \\
\hline $\mathrm{CaO}$ & 61.43 & 3.48 & 15.50 & 35.09 \\
$\mathrm{SiO}_{2}$ & 20.77 & 60.78 & 46.97 & 37.55 \\
$\mathrm{Al}_{2} \mathrm{O}_{3}$ & 5.55 & 21.68 & 11.86 & 10.55 \\
$\mathrm{Fe}_{2} \mathrm{O}_{3}$ & 3.35 & 5.48 & 7.98 & 0.28 \\
$\mathrm{MgO}$ & 2.49 & 1.71 & 6.51 & 7.92 \\
$\mathrm{SO}_{3}$ & 2.49 & 0.34 & 3.47 & 2.95 \\
$\mathrm{~K}_{2} \mathrm{O}$ & 0.77 & 1.95 & 3.23 & 1.07 \\
$\mathrm{Na}_{2} \mathrm{O}$ & 0.19 & 0.74 & 2.33 & 0.24 \\
$\mathrm{Loss}_{\text {on ignition }}$ & 2.20 & 1.57 & 0.45 & 2.79 \\
$\mathrm{SiO}_{2}+\mathrm{Al}_{2} \mathrm{O}_{3}+\mathrm{Fe}_{2} \mathrm{O}_{3}$ & 29.37 & 87.94 & 66.81 & 48.38 \\
& & & & \\
Physical properties & & & & \\
Specific gravity & 3.06 & 2.10 & 2.27 & 2.79 \\
Blaine fineness $\left(\mathrm{m}^{2} / \mathrm{kg}\right)$ & 325 & 290 & 306 & 425 \\
\hline
\end{tabular}

necessary to have low matrix toughness for obtaining strain-hardening behavior and many closely spaced microcracks. However, with the increase of aggregate amount and size, toughness of the matrix increases and accordingly, maximum aggregate size that would be used in the mix is being restricted through this way. Therefore, in the production of ECC, to minimize the mortar matrix fracture toughness, no large aggregates were used and quartz sand with maximum aggregate size of $400 \mu \mathrm{m}$ was incorporated to achieve the desired characteristics. To improve the workability of ECC mixtures, HRWRA (polycarboxylate ether as an active ingredient with specific gravity of 1.1 and $40 \%$ solid content) was used until the desired fresh ECC characteristics were obtained. The dimensions of the PVA fiber are $8 \mathrm{~mm}$ in length and $39 \mu \mathrm{m}$ in diameter. The nominal tensile strength of the fiber is $1610 \mathrm{MPa}$ and the density of the fiber is $1300 \mathrm{~kg} / \mathrm{m}^{3}$. The PVA fiber is surface-coated by hydrophobic oil (1.2\% by weight) to reduce the fiber/matrix interfacial bond strength. To account for material inhomogeneity, a fiber content of $2 \%$ by volume in excess of the calculated critical fiber content has been typically used in the mixture design. These decisions were made through ECC micromechanics material design theory and have been experimentally demonstrated to produce good ECC properties [16].

To determine the splitting tensile strength and chloride ion permeability behavior of the ECC mixtures, $\emptyset 100 \times 200 \mathrm{~mm}$ cylinder specimens were prepared. The molds were stripped after $24 \mathrm{~h}$. and the cylinder specimens were placed in lime saturated water at $23 \pm 2{ }^{\circ} \mathrm{C}$ for 60 days. This long-term curing period underwater ensures an advanced degree of both Portland cement hydration and pozzolanic activity. For the flexural and compressive strengths characterizations of the ECC mixtures, $360 \times 50 \times 75 \mathrm{~mm}$ prism specimens and $50 \mathrm{~mm}$-cubic specimens were prepared, respectively. All specimens were demoulded at the age of $24 \mathrm{~h}$, and moisture cured in plastic bags at $95 \pm 5 \% \mathrm{RH}, 23{ }^{\circ} \mathrm{C}$ for 7 days. The specimens were then air cured in laboratory at $50 \pm 5 \% \mathrm{RH}, 23^{\circ} \mathrm{C}$ until the age of testing.

Four-point bending tests were performed on a closed-loop controlled material testing system at a loading rate of $0.005 \mathrm{~mm} / \mathrm{s}$. The span length of flexural loading was $304 \mathrm{~mm}$ with a $101 \mathrm{~mm}$ center span length. During the flexural tests, the load and mid-span deflection were recorded on a computerized data recording

Table 1

ECC mixture proportions

\begin{tabular}{|c|c|c|c|c|c|c|c|}
\hline Mix ID. & Cement & $\mathrm{W} / \mathrm{CM}$ & Aggregate/binder ratio & $\mathrm{FA} / \mathrm{PC}$ & $\mathrm{S} / \mathrm{PC}$ & PVA, by volume (\%) & HRWR $\left(\mathrm{kg} / \mathrm{m}^{3}\right)$ \\
\hline F_ECC & 1 & 0.27 & 0.36 & 2.2 & - & 2 & 3.8 \\
\hline C_ECC & 1 & 0.27 & 0.36 & 2.2 & - & 2 & 4.2 \\
\hline S_ECC & 1 & 0.27 & 0.36 & - & 2.2 & 2 & 4.5 \\
\hline
\end{tabular}




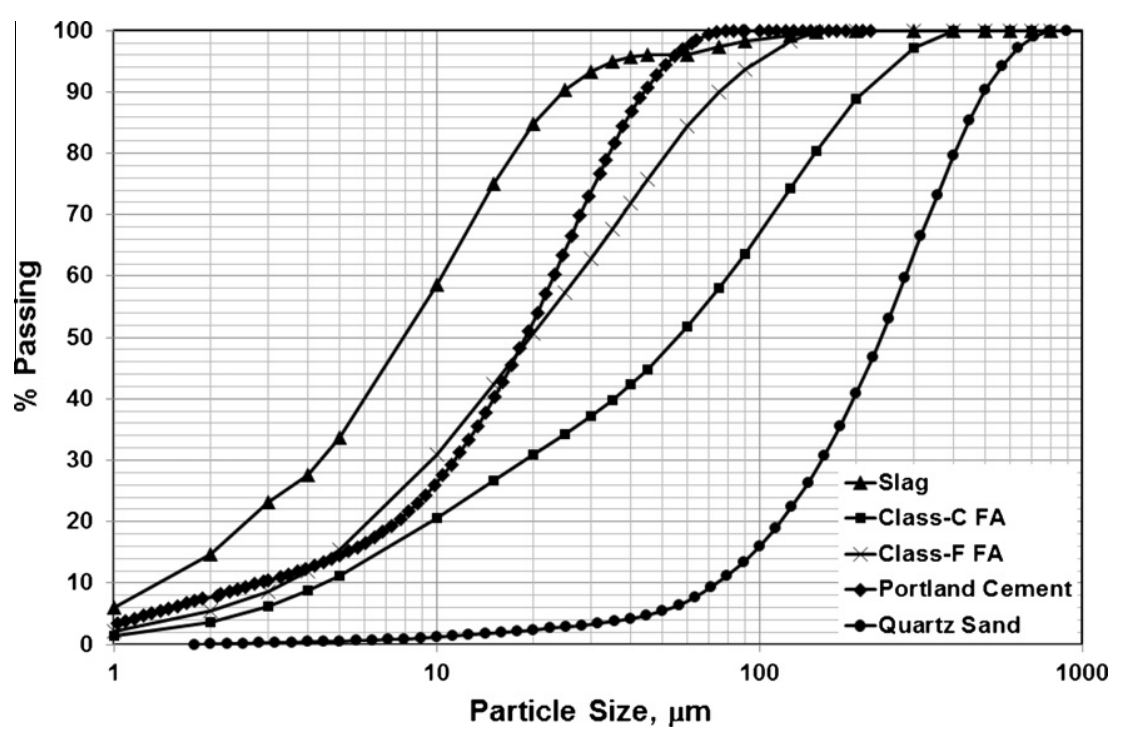

Fig. 1. Particle size distributions of sand, Portland cement and SCMs.

system. A LVDT was fixed on the test set-up to measure the flexural deflection of the specimen. In the flexural load-deformation curves, the maximum stress is defined as the flexural strength (modulus of rupture - MOR), and the corresponding deflection is defined as the flexural deformation capacity.

\subsection{Pre-cracking and self-healing evaluation methods}

At the end of 60 days of water immersion, all cylindrical specimens were evenly divided into three $50 \mathrm{~mm}$ pieces with the help of diamond blade saw. Since ratio of W/CM is fixed, curing conditions and the testing age are same for all mixtures, the effect of SCM on test results is dominant. To derive the splitting tensile stressdeflection relation of the ECC mixtures, at the age of 60 days, four cylindrical specimens $(\varnothing 100 \times 50 \mathrm{~mm})$ from each mixture were loaded up to failure. Plywood strips were placed between the loading plates and the specimen to prevent the specimens from crushing at the loading points. As presented in Table 3, both the ultimate splitting load carrying capacities and ultimate splitting deformation capacities of ECC mixtures with different SCMs were close each other. Therefore, it has been decided to pre-crack the cylindrical specimens by loading to $1.00 \mathrm{~mm}, 1.25 \mathrm{~mm}$ and up to failure deformation levels under splitting tensile loading at a loading rate of $0.005 \mathrm{~mm} / \mathrm{s}$ to obtain different levels of microcrack damage before being exposed to different curing regimes. After reaching the predetermined deformation levels, the specimens were unloaded, and removed from the universal test machine to prepare for exposure to different environments. Upon unloading, crack characteristics were analyzed using an optical microscope with the maximum magnification of $125 \mathrm{X}$. Preloaded specimens up to failure showed localized large cracks with crack width of more than $200 \mu \mathrm{m}$. On the other hand, due to the high tensile ductility of ECC, the specimens preloaded to a deformation level of up to $1.25 \mathrm{~mm}$ remain in the deformation-hardening stage, displaying microcrack damage but no localized large cracks. For the specimens not loaded up to failure, split tensile loading caused cracks with widths between 50 and $140 \mu \mathrm{m}$, and many cracks with width less than $20 \mu \mathrm{m}$ were also observed. Among the ECC mixtures studied, S_ECC samples had a wider average crack width compared to the FA-ECC (F_ECC and C_ECC) samples.

At the age of 60 days, the rapid chloride permeability testing (RCPT), based on the ASTM C1202, was conducted on the precracked and virgin ECC specimens to determine whether microcracking due to mechanical pre-loading affects chloride ion penetration resistance or not. The RCPT is virtually a measurement of electrical conductivity of concrete, an indirect measure of chloride penetrability [17], which depends on both the pore structure characteristics and pore solution chemistry of concrete. However, it has been stressed by Misra et al. [18] that chloride permeability as measured from RCPT can be used for quality control of concrete. As more chloride ions migrate into the ECC specimen, more current can pass through, and the total charge passed during $6 \mathrm{~h}$. increases. A high value for total charge passed indicates that the ECC is highly penetrable.

The pre-loaded ECC disc specimens together with uncracked (virgin) disc specimens were subjected to different exposure conditions at room temperature for 30 and 60 days before testing to determine how much healing occurred in terms of rapid chloride permeability. Three different conditioning regimes were used to simulate different environmental exposures and to investigate their influences on the rapid chloride ion permeability of ECC mixtures at different ages by using four disc specimens at each age. Therefore, the self-healing effect was deduced from the change in RCPT results. Three different conditioning regimes are detailed below.

Table 3

Basic mechanical properties of ECC mixtures.

\begin{tabular}{|c|c|c|c|c|c|c|c|c|c|}
\hline \multirow[t]{2}{*}{ Mechanical properties } & \multicolumn{3}{|l|}{ F_ECC } & \multicolumn{3}{|l|}{ C_ECC } & \multicolumn{3}{|l|}{ S_ECC } \\
\hline & 7 day & 28 day & 60 day & 7 day & 28 day & 60 day & 7 day & 28 day & 60 day \\
\hline Compressive strength (MPa) & 21.2 & 35.1 & 51.3 & 26.3 & 46.7 & 56.7 & 50.5 & 72.5 & 75.1 \\
\hline Flexural strength (MPa) & 6.7 & 9.6 & 10.6 & 6.8 & 8.7 & 10.5 & 9.6 & 12.0 & 12.2 \\
\hline Flexural deformation (mm) & 5.2 & 5.5 & 3.5 & 4.5 & 3.6 & 3.4 & 4.1 & 3.5 & 3.2 \\
\hline Splitting tensile strength (MPa) & - & - & 4.1 & - & - & 4.3 & - & - & 5.8 \\
\hline Splitting deformation (mm) & - & - & 1.67 & - & - & 1.56 & - & - & 1.45 \\
\hline
\end{tabular}


- The first conditioning regime (CA - continuous air) considered direct exposure to laboratory air at $23^{\circ} \mathrm{C}, 50 \pm 5 \% \mathrm{RH}$ until the predetermined testing ages. This conditioning is used as the reference curing regime.

- The second conditioning regime ( $\mathrm{CW}$ - continuous wet) consisted of submersion in water at $23^{\circ} \mathrm{C}$ until the predetermined testing ages. This regime is used to simulate underwater structures.

- The third conditioning regime (F/T - freeze/thaw cycle) considered ASTM C666 procedure-A conditions [19]: the specimens were kept in fully saturated condition with temperature cycling between -17.8 and $4.4{ }^{\circ} \mathrm{C}$, each cycle being around $5 \mathrm{~h}$. Each complete $5 * *$ cycle therefore represents 1 day of exposure. The resulting data is important in view of the growing use of ECC, especially for highway pavements, airport pavements, and bridge decks in cold climate regions.

Another method used to investigate autogenous healing in this study incorporated a scanning electron microscope (SEM) to observe self-healing products. X-ray diffraction (XRD) analysis technique was also used to chemically analyze healing products. These techniques are particularly useful in verifying the chemical makeup of self-healing compounds, essential in identifying the chemical precursors to self-healing and ensuring their presence within the composite.

\section{Results and discussions}

\subsection{Basic mechanical behavior}

At the ages of 7, 28 and 60 days, compressive strength tests for cubic specimens were applied following ASTM C39 procedures [20]. Table 3 tabulates the average of compressive strength results as determined from at least six cubic specimens. As it is seen from Table 3, for the first 7 days of curing, strength gain in the specimens casted with slag (S_ECC) was significantly higher compared to the mixtures casted with fly ash (F_ECC and C_ECC) but between the ages of 28 days and 60 days high amount of strength gain was achieved by FA-ECC mixtures. This finding was partially a result of the advances in hydration and pozzolanic reactions of the slag due to its large specific surface area $\left(425 \mathrm{~m}^{2} / \mathrm{kg}\right.$ surface area) compared to that of fly ashes $\left(290 \mathrm{~m}^{2} / \mathrm{kg}\right.$ for Class-F FA and $306 \mathrm{~m}^{2} / \mathrm{kg}$ for Class-C FA). Due to the smaller average particle size of slag than that of cement, it can well fill the space among the cement grains (filler effect), improving the particle distribution of cementitious system, and forming dense microstructure. Moreover, high surface area of slag provides more nucleating sites and $\mathrm{OH}^{-}$ions as well as alkalis into the pore fluid [21]. At the ages of 7 days of curing, the compressive strength test results were similar for both F_ECC and C_ECC mixtures. However, the strength gain was more pronounced for C_ECC beyond 7 days of curing. This high strength should be correlated not only to the fineness but also to the self-cementitious activity of Class-C FA. The lime content of FA seems to contribute to the strength of ECC mixture. Nevertheless, all the mixtures exceeded the nominal compressive strength for normal concrete ( $30 \mathrm{MPa}$ ) at the age of 28 days which is an acceptable value for most of the construction practices.

The direct tensile test is considered to be the most accurate method to confirm the strain-hardening behavior of a composite, as quasi-brittle fiber reinforced composites can potentially show apparent strain-hardening behavior under flexural loading, depending on the specimen geometry. However, previous studies demonstrate that deflection capacity under bending can be correlated with the tensile strain capacity when the material is truly strain hardening [22]. Therefore, in this study, it was decided to use the four-point bending test to investigate the flexural strength and ductility of ECC mixtures.

During the four-point bending test, in all ECC specimens, the first crack was observed at the tensile face in the mid-span. As flexural stress increased, multiple cracks with small spacing and tight widths developed and propagated from the first cracking point. When the fiber bridging strength is reached for one of the microcracks, bending failure resulting in localized deformation occurred at that part of ECC specimen. As the modulus of rupture (MOR) was approached, one of the cracks inside the mid-span started to widen leading to complete failure.

The test results in terms of flexural strength (MOR) and ultimate mid-span deflection at the peak stress at the end of 7, 28 and 60 days are displayed in Table 3 . The flexural performances of ECC mixtures were calculated by averaging the results of six four-point bending measurements. It is important to note that the coefficient of variations of the flexural strength test results within each mix design is lower than $10 \%$. MOR values varied from 6.7 to $9.6 \mathrm{MPa}$ showing that increase in the values of flexural strength of S_ECC was not so drastic compared to the values of F_ECC and C_ECC for the first 7 days as in the compressive strength test results. Moreover, for all specimens, no significant flexural strength gain was observed beyond the age of 7 days. The most probable reason for this trend may be attributed to the fact that flexural strength is governed by more complex material properties, such as tensile first cracking strength, ultimate tensile strength and tensile strain capacity, particularly in the case of strain hardening cementitious materials [14].

Ultimate mid-span deflection capacity, which reflects the material ductility, of the mixtures ranged between the values of 4.1 and $5.2 \mathrm{~mm}$ for the first 7 days. From 7 days to 60 days, for all mixtures, there is a slight decrease due to the continuous evolution of fiber/ matrix interface properties. Among all the supplementary cementitious materials, F_ECC showed the highest deflection capacity, therefore ductility, at all ages. The improvement in the mid-span beam deflection capacity with the use of Class-F FA can be attributed to the fact that the addition of Class-F FA has a tendency to reduce PVA fiber/matrix interface chemical bond and matrix toughness while increasing the interface frictional bond, in favor of attaining high tensile strain capacity [13]. However, although it is not sure, the overall decrease in the mid-span beam deflection capacity for C_ECC specimens might be associated with higher lime content which in turn causes enhanced fracture toughness, bond strength and the chemical bond between mortar matrix and fibers as in S_ECC specimens.

\subsection{Rapid chloride permeability test}

\subsubsection{Unhealed specimens}

The results of chloride permeability tests for each ECC mixture were demonstrated in Table 4. Specimens were tested at the age of 60 days to fulfill the requirements needed for more mature paste, and not to have contradictory results due to different characteristics of SCMs. As explained in previous sections, specimens were divided into three categories as preloaded to $0 \mathrm{~mm}$ (pristine), $1.00 \mathrm{~mm}$ and $1.25 \mathrm{~mm}$ deformation levels. Additionally, for the specimens exposed to $\mathrm{CW}$ curing regime, four more disc specimens were loaded up to failure at the ages of 60 days for comparison. RCPT results were recorded in coulombs at the ages of 60 , $60+30$ and $60+60$ days, respectively.

As seen from Table 4, after 60 days of moist curing exposure S_ECC exhibited the lowest charge $(468 \mathrm{C})$, then high-lime FA $(1787 \mathrm{C})$, and low-lime FA the highest (3867 C). It, therefore, appears that the FA-ECC mixtures (F_ECC and C_ECC) were more permeable than the S_ECC mixture in accordance with RCPT results. 
Table 4

Rapid chloride permeability test results of ECC specimens.

\begin{tabular}{|c|c|c|c|c|c|c|c|c|}
\hline \multicolumn{2}{|c|}{ Preloading deformation level } & \multirow{2}{*}{$\begin{array}{l}60 \text { day } \\
\mathrm{CW}\end{array}$} & \multicolumn{3}{|c|}{$60+30$ day } & \multicolumn{3}{|c|}{$60+60$ day } \\
\hline & & & CW & $\mathrm{F} / \mathrm{T}$ & $\mathrm{CA}$ & $\mathrm{CW}$ & $\mathrm{F} / \mathrm{T}$ & CA \\
\hline \multirow[t]{4}{*}{ F_ECC } & $0 \mathrm{~mm}^{\mathrm{a}}$ & 3867 & 1582 & 3880 & 2886 & 703 & 4267 & 1892 \\
\hline & $1.00 \mathrm{~mm}^{\mathrm{a}}$ & 4358 & 1691 & 4339 & 3111 & 817 & 5291 & 2285 \\
\hline & $1.25 \mathrm{~mm}^{\mathrm{a}}$ & 4964 & 1757 & 4850 & 3627 & 1104 & 5946 & 2608 \\
\hline & Up to failure & 6767 & 2172 & - & - & 1242 & - & - \\
\hline \multirow[t]{4}{*}{ C_ECC } & $0 \mathrm{~mm}$ & 1787 & 480 & 1534 & 715 & 161 & 1953 & 432 \\
\hline & $1.00 \mathrm{~mm}$ & 2066 & 531 & 1760 & 931 & 255 & 2226 & 570 \\
\hline & $1.25 \mathrm{~mm}$ & 2214 & 648 & 1927 & 1194 & 312 & 2339 & 619 \\
\hline & Up to failure & 2537 & 882 & - & - & 370 & - & - \\
\hline \multirow[t]{4}{*}{ S_ECC } & $0 \mathrm{~mm}$ & 468 & 284 & 344 & 329 & 245 & 378 & 254 \\
\hline & $1.00 \mathrm{~mm}$ & 764 & 315 & 527 & 462 & 274 & 614 & 373 \\
\hline & $1.25 \mathrm{~mm}$ & 1027 & 372 & 736 & 651 & 317 & 833 & 499 \\
\hline & Up to failure & 1371 & 530 & - & - & 427 & - & - \\
\hline
\end{tabular}

a Displacements on $100 \mathrm{~mm} \times 50 \mathrm{~mm}$ disks tested in splitting.

The permeability difference can be discussed in related to SCM particle size, modification of pore size distribution due to pozzolanic and cementitious reaction and pore solution chemistry or electrical conductivity changes. The following facts are taken into consideration for the evaluation of permeability of different SCMs: (1) Class-F FA has a much coarser particle size than Class-C FA (Fig. 1); (2) slag has the finest particle size and (3) available $\mathrm{Na}_{2} \mathrm{O}$ equivalent alkali percentages by ASTM C33 are different for different SCMs (Class-F FA: $2.02 \%$, Class-C FA: $4.45 \%$ and slag: $0.94 \%$ ). Because slag has the finest particle size and lowest available alkali content, S_ECC mix has the lowest permeability among ECC mixtures. Class-C FA has higher equivalent alkali content than Class-F FA but finer particle size. This suggests that pore size distribution may be more related to chloride penetrability and thus the effect of Class-C FA replacement on chloride penetrability is due to a decrease in the pore size opening.

To investigate the effect of pore structure on ECCs' chloride permeability, the porosity and pore size distribution study was also carried out with mercury intrusion porosimetry (MIP) testing at the age of 60 days. The cumulative intruded pore volume curves for ECC mixtures with different SCMs, obtained from MIP, are provided in Fig. 2a. This figure indicates that compared to S_ECC mixture, the total intruded volume of mercury per gram of the sample increases with the use of FA in ECC production. This increasing effect is, especially, more pronounced with the use of Class-F FA. It has been suggested that since different pore size affect different properties, the pore size distribution, not the total capillary porosity, is a better criterion for evaluating the impermeability characteristics of a hydrated cement paste. Macrocapillary voids larger than $50 \mathrm{~nm}$ are generally accepted to be more influential in determining the permeability characteristics of hydrated cementbased materials [23]. Fig. 2b shows the normalized volumes of mercury intrusion in a specified range of pores (greater than $50 \mathrm{~nm}$ and $4-50 \mathrm{~nm}$ ) for ECC mixtures. Analysis of the pore size distribution data shows that a similar trend of pore size distribution can be observed in S_ECC and C_ECC mixtures, and F_ECC has a significantly higher proportion of pore sizes within the macropores limits than C_ECC and S_ECC mixtures, as shown in Fig. 2 b. The proportion of pores within the macropores classification ranges from $52.9 \%$ for F_ECC compared with $37.5 \%$ for C_ECC and $32.7 \%$ for S_ECC. The higher total volume of macropores in F_ECC could explain the higher magnitude of chloride permeability of pristine F_ECC specimens at the age of 60 days.

This test result does not agree with the previous studies [24,25], which found that use of SCMs, especially FA, inhibits the ingress of chloride. Fig. 3 displays that, the microstructure changed greatly with the incorporation of high volume Class-F FA and significant amount of FA particles without any chemical reaction could be observed in the matrix even after 60 days of $\mathrm{CW}$ curing, which relatively influences the intensity of matrix. However, this is not the case for Class-C FA and slag; the matrix microstructure changed greatly, with the incorporation of Class-C FA slight and with the incorporation of slag and almost none unhydrated particles could be observed showing that the material is less penetrable. This result is in agreement with the widely acknowledged fact that FA (especially Class-F FA) content beyond 30-40\% does not participate in the hydration process thus delays the hydration process [26]. In HVFA ECC, however, secondary hydration of FA may only reach a very limited reaction degree because the FA content is relatively high in proportion to cement, and it may remain in the system
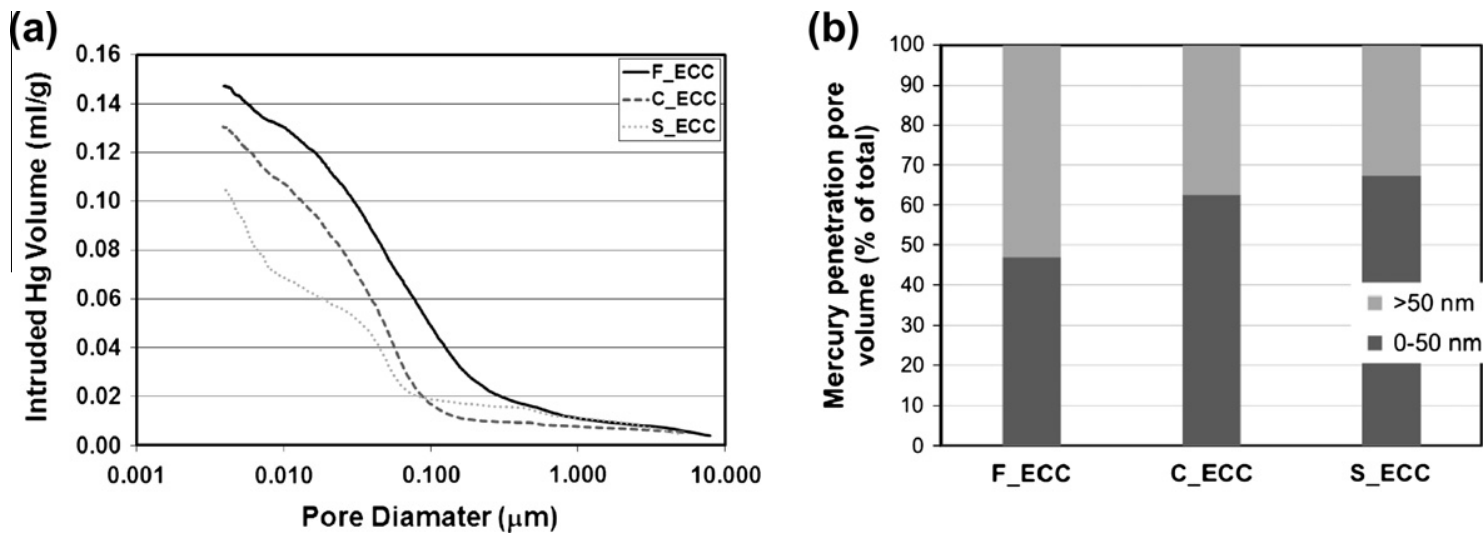

Fig. 2. Changes in pore size distribution of ECC mixtures. 


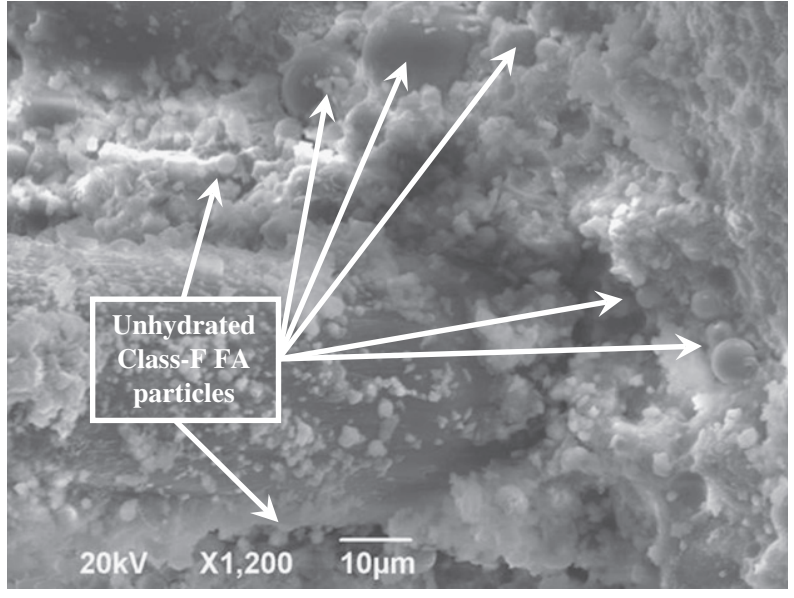

Fig. 3. SEM observations of F_ECC mixture at 60 days of age.

as fillers even after a long time of curing. The benefits of a higher FA content are expected to manifest at later ages with the continuous supply of moisture and presence of $\mathrm{CH}$ in the hydrated matrix [24].

Chloride ion permeability test results of the preloaded specimens for ECC mixtures at 60 days are presented in Table 4 and Fig. 4. The test results are expressed in terms of the total electrical charge in coulombs, which provides an indirect measure of the resistance of precracked ECC specimens to chloride ion penetration according to the ASTM C1202. The classification ranges given in the ASTM C1202 are also illustrated graphically in Fig. 4 by horizontal gridlines. As mentioned earlier, maximum splitting tensile deformation capacities of all ECC mixtures at 60 days was around $1.5 \mathrm{~mm}$. Specimens were, therefore, preloaded to deformation levels of 1.00 and $1.25 \mathrm{~mm}$ and up to failure. After unloading, multiple microcracks with a small average crack width and fine crack spacing were observed on all specimens. The measured average crack width is about $110 \mu \mathrm{m}$ for S_ECC mixtures, $65 \mu \mathrm{m}$ for C_ECC mixtures and $50 \mu \mathrm{m}$ for F_ECC mixtures at 60 days age. Increasing the preloading deformation level leads to higher number of cracks. As these specimens were tested right after the release of pre-loading at the ages of 60 days, they had no time to undergo any crack healing. Properties of pristine specimens (preloading deformation level of $0 \mathrm{~mm}$ ) are also shown in this figure.

In literature, although many researchers [27] have argued that the permeation of concretes with crack width less than $100 \mu \mathrm{m}$ generally behave like sound concrete, as seen from the figure, the presence of microcracking in ECC significantly alters the chloride ion transport properties measured as a function of the pre-loading deformation level. The chloride ion permeability rate as measured by RCPT increases with the number of microcracks associated with a particular preloading deformation level. In particular, for the highly damaged ECC specimens (loaded $\geqslant 1.25 \mathrm{~mm}$ deformation level), the measured chloride ion permeability rate was very fast thereby implying that microcracks induced by mechanical loading facilitated the chloride ion ingress in ECC. However, the increase was low for S_ECC specimens, and even for specimens loaded up to failure, S_ECC mixture exhibited high resistance (low penetration class according to ASTM C1202) to chloride ion penetration with the total charge exceeding $1371 \mathrm{C}$ in average for the failed specimen at the age of 60 days. On the other hand, use of FA in ECC production reduces the resistance to chloride-ion penetration of preloaded ECC specimens. This effect is more negatively influenced with the use of Class-F FA. At all stages, precracked F_ECC specimens were several times more conductive than those of C_ECC and S_ECC specimens. This may be attributed to the fact that the use of FA, especially Class-F FA, caused a reduction in the strength capacity and a weaker interfacial transition zone at the age of the preloading. Therefore, it could be stated that the properties of newly damaged F_ECC specimens are more affected by the mechanical pre-loading than the C_ECC and S_ECC specimens.

\subsubsection{Effects of self-healing}

Chloride ion permeability values in terms of RCPT were measured before and after splitting tensile preloading for each environmental conditioning to determine the effect of type and chemical composition of SCMs on self-healing capability of composites. Fig. 4 shows the changes in chloride ion permeability of the ECC mixtures that were exposed to different curing regimes up to 60 days (CA - continuous air, CW - continuous wet, and $\mathrm{F} / \mathrm{T}$ freeze/thaw cycle). It should be recalled that these mixtures had experienced an initial 60 days continuously wet curing and preloading. Each data point given in Fig. 4 is an average of at least four specimens. For the pristine specimens, when the test results after 60 days are considered (Fig. 4), it could be seen that there is a steady reduction in the chloride ion penetration properties with time irrespective of the applied further curing conditions. For example, results obtained from pristine F_ECC specimens cured continuously in water for 60,90 and 120 days were 3867, 1582 and $703 \mathrm{C}$, respectively. This result shows that for the first further 30 days of moist curing 59\%, and for another further 30 days of curing $56 \%$ refinement in chloride permeability was attained. These rates are $73 \%$ and $66 \%$ for C_ECC and $40 \%$ and $14 \%$ for S_ECC at stated ages of curing.

The reason for FA-ECC mixtures to exhibit notable improvement in chloride ion permeability results of pristine specimens may be attributable to the higher amounts of unhydrated cementitious particles present in system (see Fig. 3). However, the situation was not the same for S_ECC, because highly reactive slag performed its cementing reactions at early ages leading to decreased pore size and densified matrix. It is important to note that, even though S_ECC did not exhibit remarkable improvement in chloride permeability with the further CW curing as in the FA-ECC mixtures, it still exhibited very high resistance (very low penetration class according to ASTM C1202) to chloride ion penetration with the total charge less than $500 \mathrm{C}$ in average at all ages. As mentioned earlier, contrary to the expectance, the use of FA (especially Class-F FA) in ECC production increased the chloride ion permeability of the ECC at the 60 days as a result of inadequate curing period. However, as seen from Fig. 4, with further 60 days continuous wet curing, part of the unhydrated cementitious particles are hydrated, which reduced pore sizes and densified the matrix and decreased the chloride ion permeability values of the FA-ECC specimens drastically.

Surprisingly, with the application of CA curing, significant amount of improvement in terms of RCPT results was observed for all ECC specimens. For example, the results of chloride ion permeability of pristine F_ECC specimens were 2886 and 1892 for $60+30$ and $60+60$ days of further CA curing; the results were 715 and 432 for C_ECC, and 329 and 254 for S_ECC pristine specimens, respectively. It is surprising to observe this amount of improvement in permeation properties in the case of CA curing since the hydration of cementitious materials will stop completely when the internal humidity in hardened cement paste falls below $80 \%$ [28]. During air curing period, the water in the isolated pores of hardened ECC mixtures can be used for further hydration and pozzolanic reaction, which could be one of the main reasons of reduced chloride ion permeability of CA cured ECC specimens. The reduction in RCPT results might also be attributed to the change on the composition of the pore solution with time, which can influence the electrical conductivity, and therefore chloride permeability test value of air-cured ECC mixtures. 


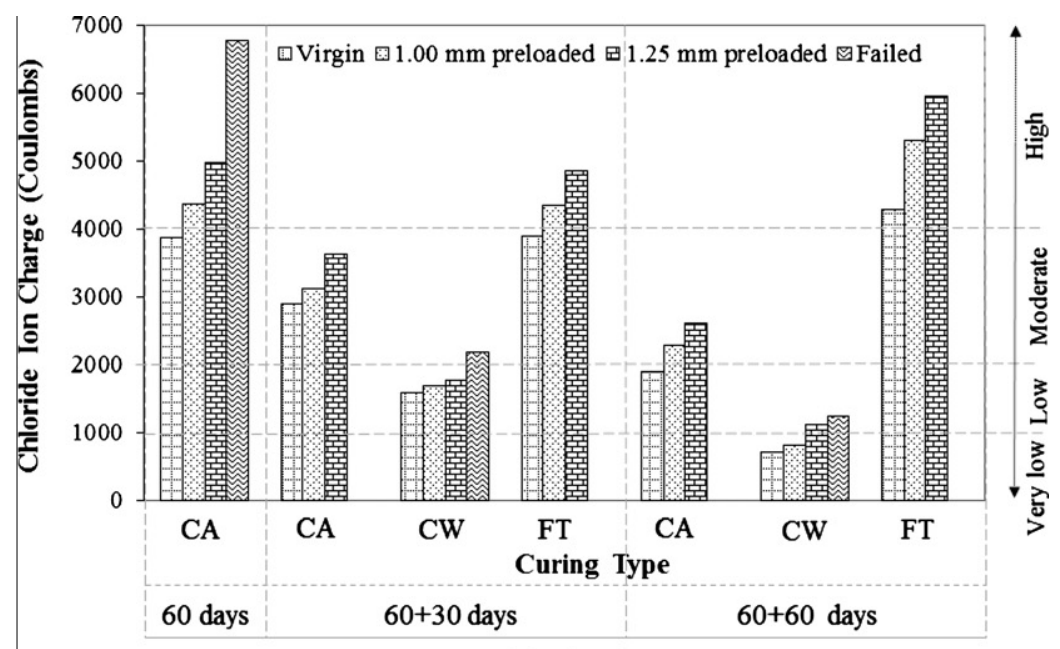

Testing Age

(a) F_ECC

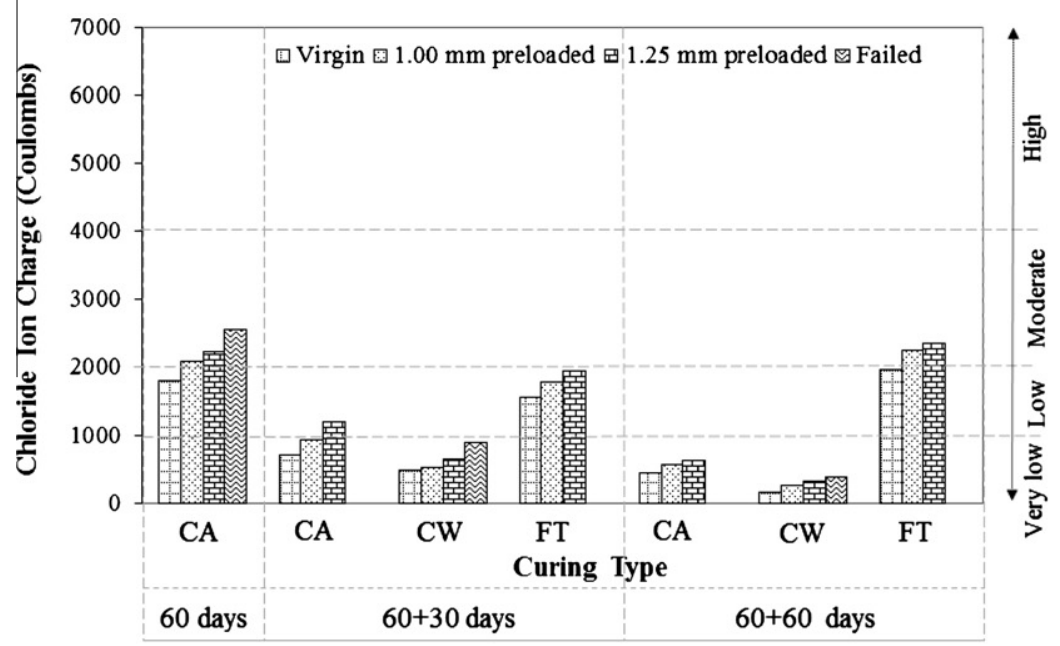

Testing Age

(b) C_ECC

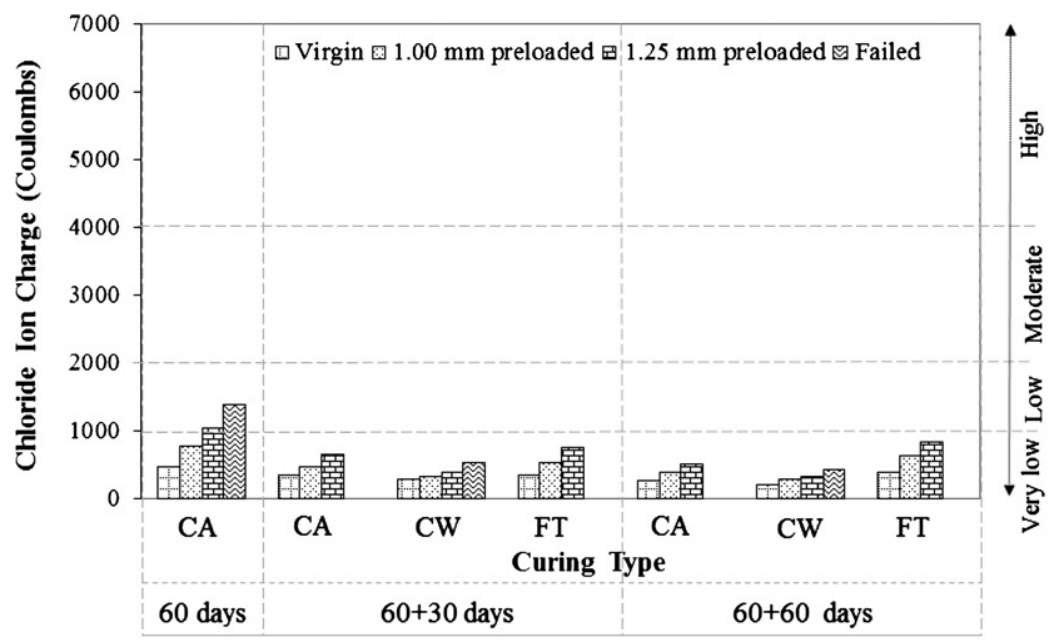

Testing Age

(c) S_ECC

Fig. 4. Chloride ion permeability values of the ECC mixtures under different curing conditions and testing ages $(1.00$ and $1.25 \mathrm{~mm}$ displacements are those on $100 \mathrm{~mm} \times 50 \mathrm{~mm}$ disks tested in splitting). 

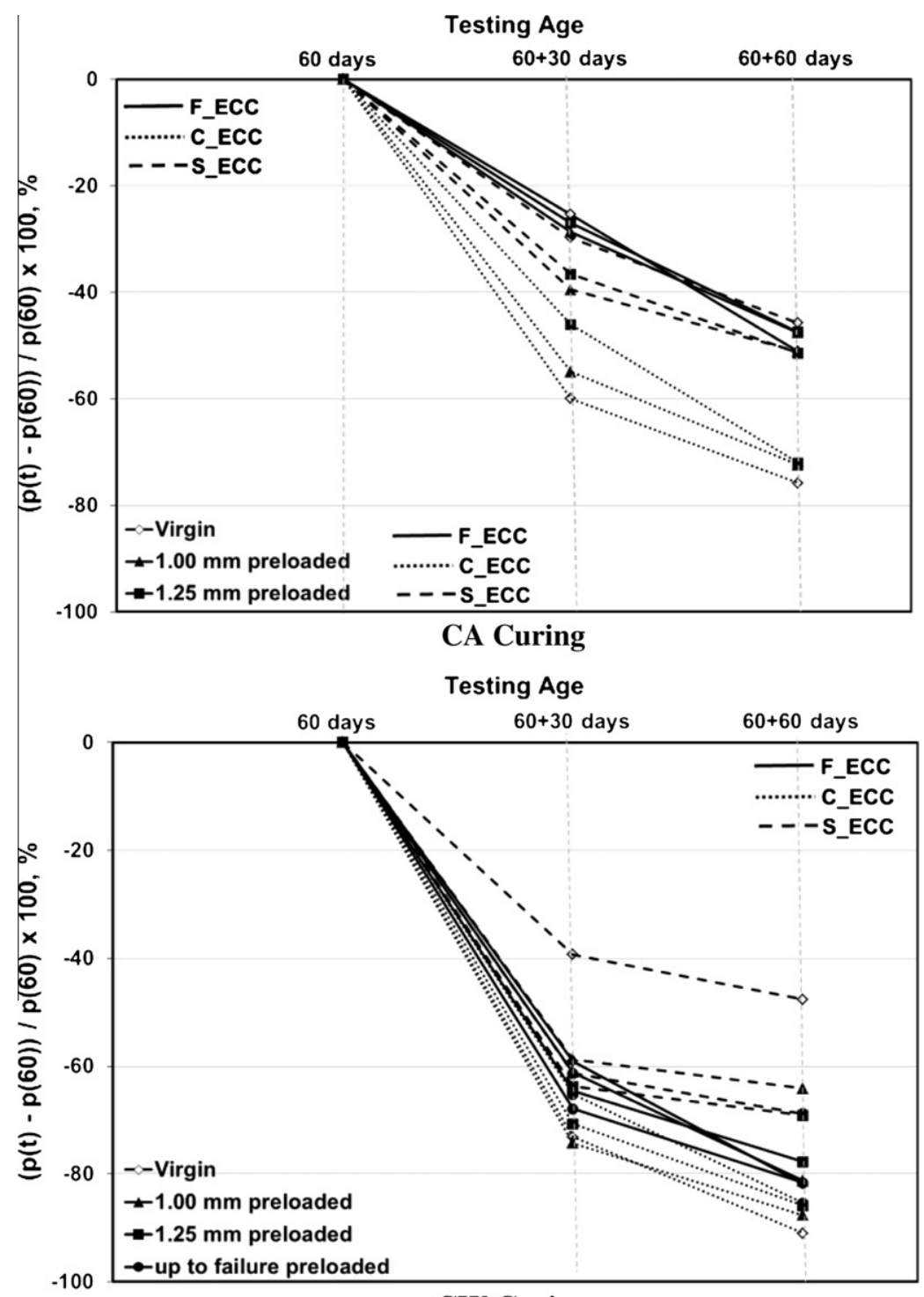

\section{CW Curing}

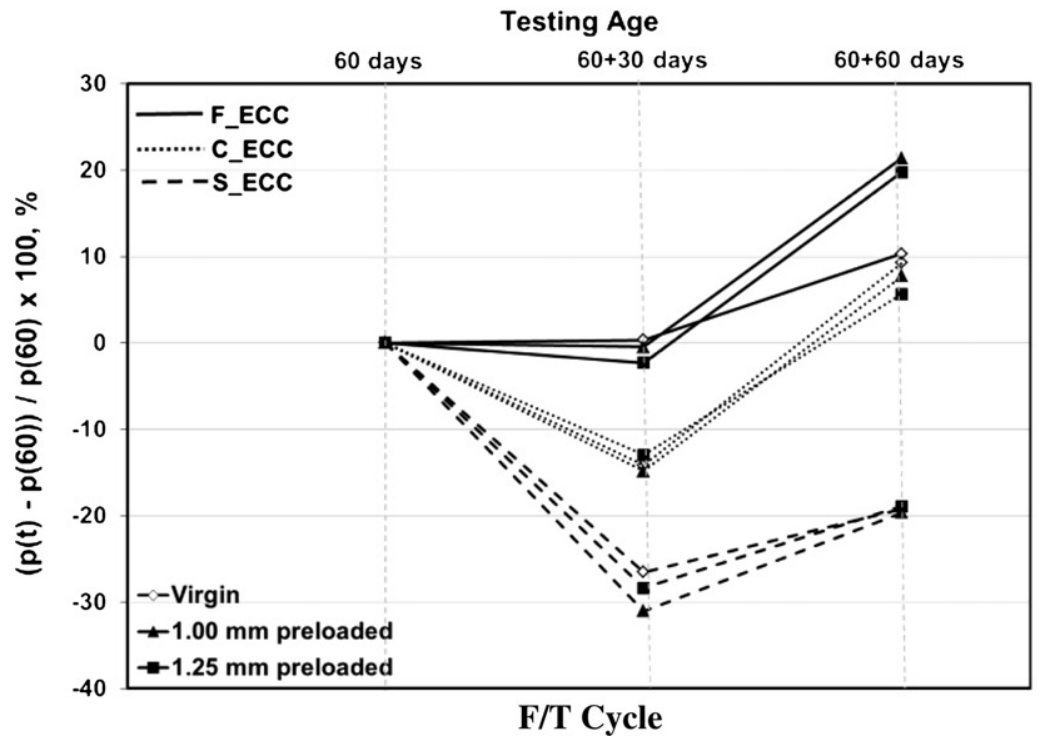

Fig. 5. Percent variations in chloride ion permeability values of ECC mixtures due to the curing regimes and testing ages. 
In Fig. 5, percent variations in chloride ion permeability values of ECC mixtures due to the effects of curing regimes and testing ages are shown. In this figure all results at a particular age and deformation level are compared with those results of 60 days of age. The values in Fig. 5 were calculated by $(p(t)-p(60)) /$ $p(60) \times 100$, where $p(t)$ and $p(60)$ denote chloride ion permeability at ages $t$ and 60 days, respectively. It is clear from Fig. 5 that RCPT results for all ECC specimens decreased as curing time extended, showing that a significant amount of self-healing is attained, except for specimens exposed to F/T cycle. As it is seen from Fig. 5, however, the change in chloride ion charge-testing age slope of CA curing conditions was not as explicit as that of CW curing conditions. Therefore, the effect of moist curing is more pronounced on the chloride ion permeability results, especially for the preloaded specimens, suggesting that water is the important parameter for further hydration reaction and self-healing to take place. As seen from Fig. 5, for CW curing, chloride ion charge-testing age slope variation of ECC mixtures was quite different for FA-ECC mixtures (F_ECC and C_ECC) and S_ECC mixture. In general, there was no meaningful variation in the chloride ion charge-testing age slope due to the applied preloading level; the decreasing trend was fairly similar for F_ECC and C_ECC specimens. For these mixtures the chloride ion penetration decreasing trend between the ages of 60 and $60+30$ days was continuous and drastic without regard to the preloading deformation level. Between the ages $60+30$ and $60+60$ days, the amount of percent variations slightly decreased irrespective of curing conditions and pre-loading deformation levels exhibiting that improvement of matrix maturity was achieved for FA-ECC specimens with the further curing. Therefore, the results of FA-ECC mixtures indicate that longer curing age, especially with the presence of moisture, leads to higher crack self-healing ability. As we know, a large amount of unhydrated cementitious materials still existed inside of FA-ECC mixtures. With increasing in curing age after preloading, more and more resultants come from further hydration filled in the tiny cracks and resulted in self-repair of damaged concrete. However, the decrease trend in chloride ion permeability of S_ECC specimens became more evident with a month of further curing only when the preloading deformation was applied. Between $60+30$ and $60+60$ days, even under continuous water curing, the chloride ion charge-testing age slope of preloaded S_ECC specimens was very low and close to zero under the CW curing.

It therefore appears that the type and chemical composition of SCM used in the production of ECC significantly influence the selfhealing rate and behavior of cementitious composites. As will be confirmed by the observations of the microstructural investigations presented in the next section, compared with S_ECC, the chloride ion permeability of ECC mixtures containing FA was recovered due to the combined effects of the further hydration processes of unhydrated cement and SCM, and formation of calcium carbonate. Thus the chloride permeability was improved much higher for the precracked ECC mixtures containing FA and experienced longer curing age. On the other hand, the formation of calcium carbonate plays the decisive part in the self-healing of cracks in S_ECC mixture. The formation of calcium carbonate is affected by the leaching of the hardened matrix [29] and from the test results of this study it is evident that the presence of cracks increased the leaching rate.

As another way of curing regime, specimens were subjected to F/T cycles. After subjected to the 150 and 300 F/T cycles, self-healing capability under $\mathrm{F} / \mathrm{T}$ cycling damage on pristine and mechanically preloaded ECC specimens was evaluated by means of RCPT changes. Since 1 day in $\mathrm{F} / \mathrm{T}$ testing machine accounts for approximately 5 cycles, it can be stated that 150 and $300 \mathrm{~F} / \mathrm{T}$ cycles took 30 and 60 days, respectively to terminate the $F / T$ test for each ECC mixtures. In Fig. 5, percent variations in chloride ion perme- ability values of ECC mixtures due to the effects of F/T cycles and testing ages were shown. As seen from Fig. 5, a slight improvement in RCPT test result was observed in all ECC mixtures up to $150 \mathrm{~F} / \mathrm{T}$ cycles. The improvement rate is more obvious for S_ECC mixture. As a result of the formation of micro-cracks due to mechanical loading, unhydrated cementitious particles are easily exposed to the water during the thawing period, which leads to development of further hydration processes. Finally micro-cracks under conditions of a damp environment were partially healed by newly formed products.

On the other hand, at the end of $300 \mathrm{~F} / \mathrm{T}$ cycles, all FA-ECC specimens regardless of preloading deformation level, showed an increase in RCPT values. The increase in chloride permeability results was more pronounced for the pre-loaded specimens. This trend is associated with the interconnection of already-existing microcracks with mechanically induced cracks leading to a further increase in overall crack size thus causing a more porous body which in turn triggers severe deterioration and increases RCPT results. The highest variation in RCPT results after frost action was observed on FA_ECC mixtures. Moreover F_ECC mixture has more deterioration than C_ECC mixture. It is, therefore, apparent from the data in Fig. 5 that the frost deterioration after $300 \mathrm{~F} / \mathrm{T}$ cycles overshadows the improvement in chloride ion transport properties of pristine and preloaded FA-ECC specimens. FA-ECC specimens also exhibited some surface scaling at the conclusion of the F/T cycling, and increased surface scaling was observed on the preloaded specimens (Fig. 6). The scaling was, however, clearly confined to the surface layers of the test specimens, and had no effect on the integrity of the ECC mass. On the other hand, compared to test result of 60 days of age, no increase in RCPT values and almost no surface scaling were observed on both pristine and preloaded S_ECC specimens after 300 cycles of F/T (Fig. 6). This was probably due to the greater maturity of the S_ECC test specimens.

When the strength properties before F/T cycling of the ECC mixtures are evaluated together (see Table 3), it can be concluded that there is a powerful relation among them. This result is in agreement with finding of the Sun et al. [30] in which different strength grades of concrete under the simultaneous action of load and $\mathrm{F} / \mathrm{T}$ cycles were studied and concluded that at the same stress ratio, concrete of higher strength could undertake more $\mathrm{F} / \mathrm{T}$ cycles, and the dynamic elastic modulus decreased more slowly with F/T cycles. With the effect of $\mathrm{CW}$ curing on further hydration processes for 60 days before being exposed to $\mathrm{F} / \mathrm{T}$ cycles, the requirements needed for more mature paste were not achieved for FA-ECC mixtures, which caused to high chloride ion permeability results and significantly scaled composite surface. Therefore, FA-ECC needs more time (maturity) to develop beneficial characteristics in terms of frost durability.

\subsection{Crack characteristics and microstructure of self-healed ECC mixtures}

At the age of 60 days, except for the control specimens, all ECC cylinder specimens were pre-cracked by applying different split-

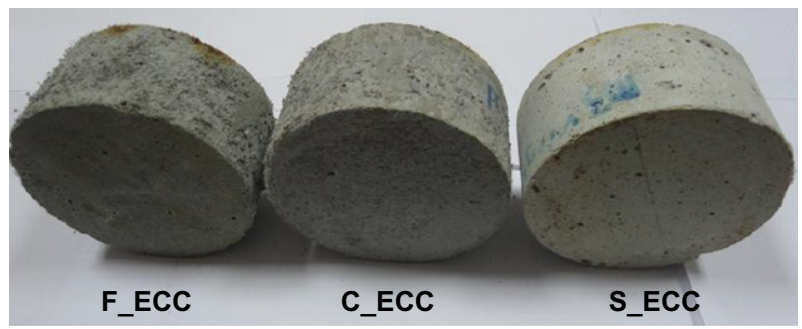

Fig. 6. Surface conditions of ECC specimens after 300 F/T cycles. 
F_ECC

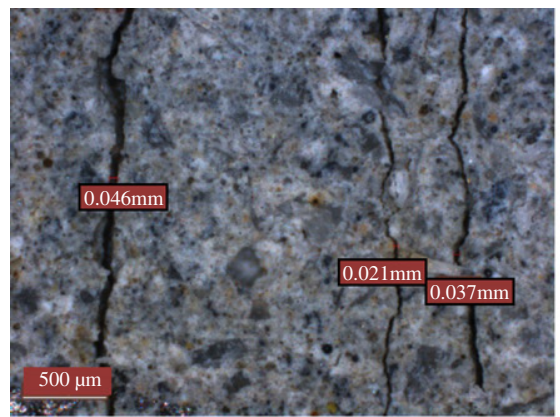

C_ECC

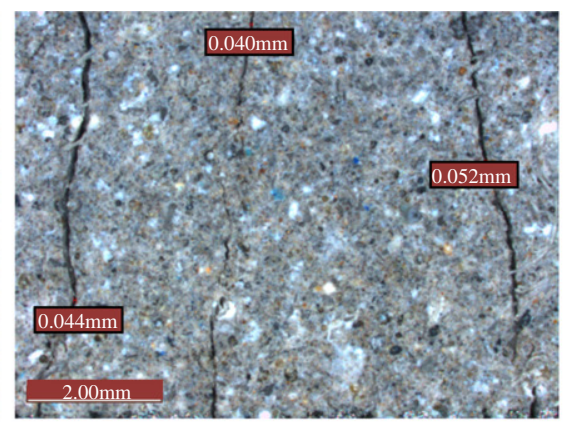

(a) Before self-healing (60 days of age)
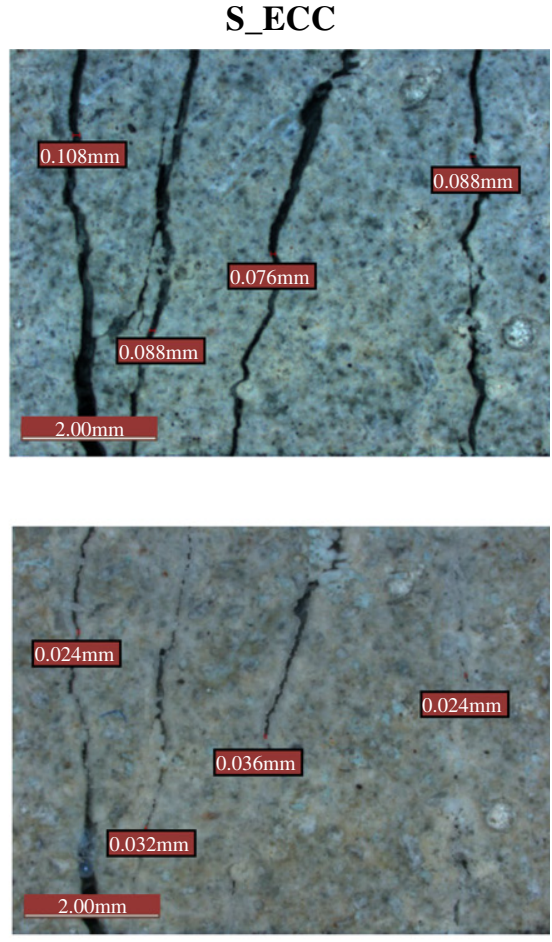

(b) After 15 days of $\mathrm{CW}$ curing

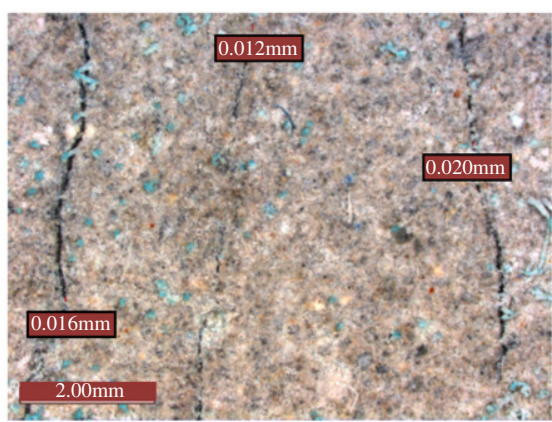

(c) After 30 days of $\mathrm{CW}$ curing

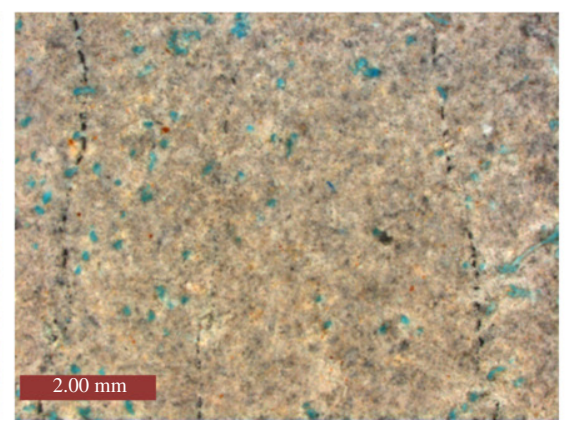

(d) After 60 days of $\mathrm{CW}$ curing
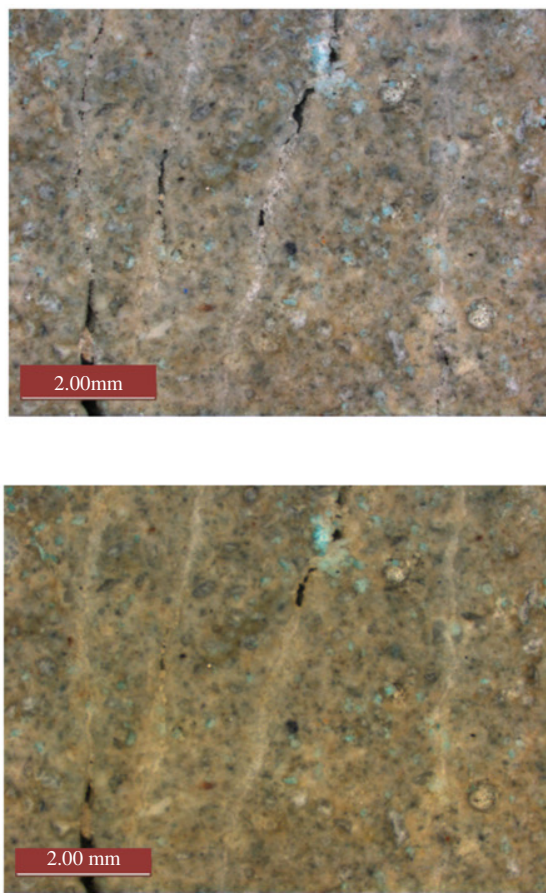

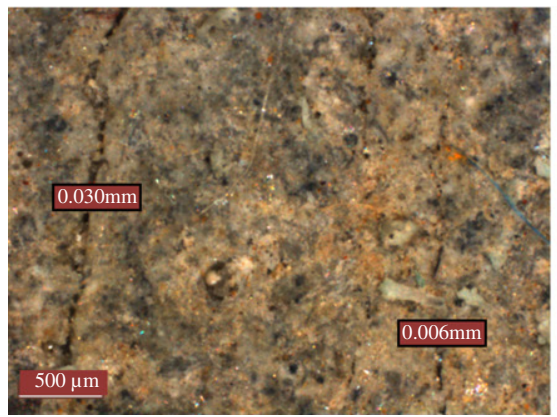

Fig. 7. Self-healing in ECC microcracks before and after exposure to CW curing.

ting deformation levels using a splitting tensile test to obtain different crack frequencies. The application of different deformation levels resulted in a different number of cracks with different average crack width for each cylinder. All ECC specimens develop multiple micro-cracking as a result of the split preload. To account for the crack closure on unloading, all crack width measurements were conducted in the unloaded state. For each specimen, a line parallel to the longitudinal axis of the cylinder specimen was drawn and the number of cracks and crack width were measured along this line using an optical microscope. Crack characteristics of the ECC specimens were investigated for all curing conditions.

At the age of 60 days, as a result of splitting tensile loading, the FA-ECC samples had a tighter average crack width compared to the S_ECC samples. Fig. 7a shows the crack damage on the surface of ECC specimens after being subjected to $1.25 \mathrm{~mm}$ splitting preloading deformation level. Fig. $7 \mathrm{~b}-\mathrm{d}$ displays an image of the same location after CW curing. As seen from Fig. 7, under the CW curing, self-healing ability was attained for all ECC mixtures up to certain 

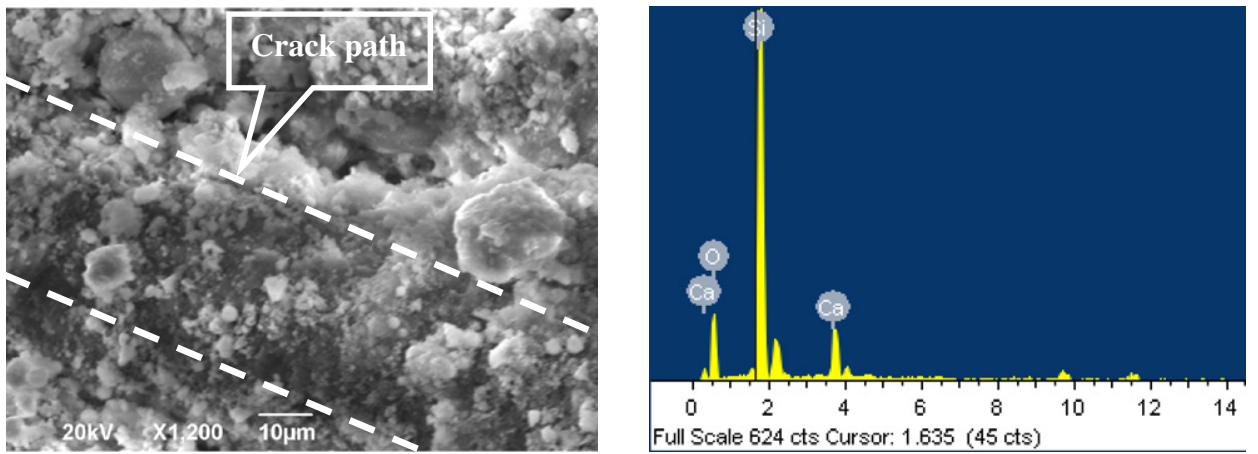

(a) F_ECC
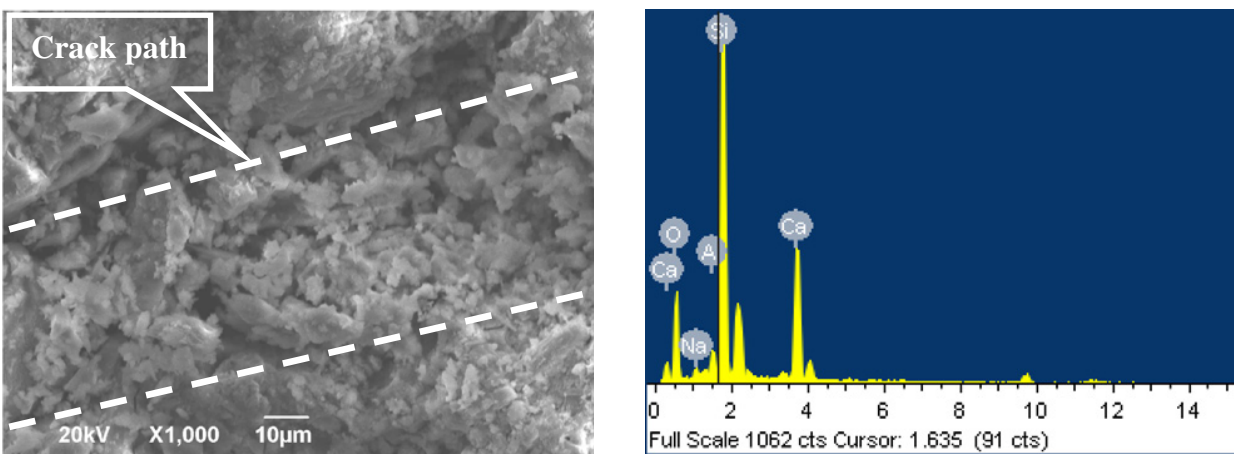

(b) $\mathrm{C} \_\mathrm{ECC}$
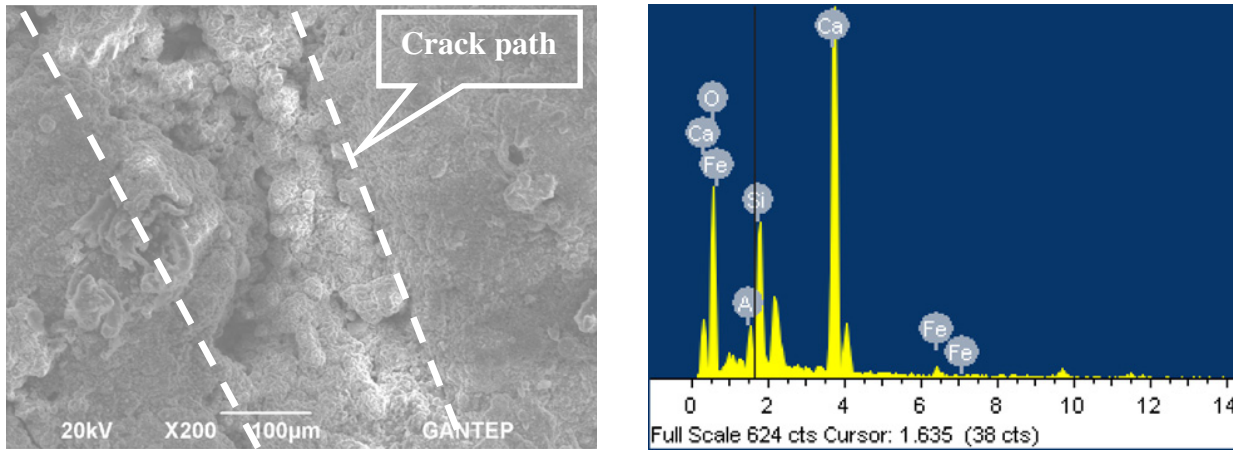

(c) $\mathrm{S} \_\mathrm{ECC}$

Fig. 8. SEM micrograph with EDX pattern of products in self-healed cracks

degree depending on the crack width and type of SCMs. On the other hand, there was no or slight decrease in the average crack width value of the specimens that were exposed to the CA curing up to $60+60$ days. Decrease in the crack width suggests that $\mathrm{CW}$ curing have greatly promoted the self-healing process and therefore enhanced the chloride ion transport properties after precracking (see Fig. 4).

Although FA-ECC samples have more unhydrated cementitious materials, and therefore, expectedly, a higher capacity for selfhealing, more evident self-healing product was observed from S_ECC mixture. It can be roughly stated that, for the further 60 days $\mathrm{CW}$ curing after pre-cracking, critical crack widths for complete self-healing to take place were about $30 \mu \mathrm{m}$ for F_ECC, $50 \mu \mathrm{m}$ for C_ECC and slightly more than $100 \mu \mathrm{m}$ for S_ECC. Even after 15 days $\mathrm{CW}$ curing, significant amount of self-healing product was observed within the cracks and near the crack faces on the S_ECC specimens' surface. These cracks of S_ECC specimens are covered by some white residue presumably due to the healing process under CW curing. On the contrast, there is almost none or slight such white residue exists on the FA-ECC samples.

To characterize the self-healing process, healing products inside the microcrack were analyzed by SEM. Typical SEM pictures (with EDX detector) for ECC samples at the age of $60+60$ days of CW curing are compared in Fig. 8. As seen from the figure, the $\mathrm{CW}$ cured samples of ECC mixtures with different crack width appear to be completely healed. Surface chemical composition analysis via EDX reveals that the microcracks of FA-ECC samples with width of less than $50 \mu \mathrm{m}$ were partly or completely filled with a mixture of $\mathrm{C}-\mathrm{S}-\mathrm{H}$ gels and calcite particles (Fig. 8a and b), which are very likely due to the continuous hydration and pozzolanic reaction of SCM. On the other hand, the observations under SEM and XEDS confirmed that the microcracks with width of slightly wider than $100 \mu \mathrm{m}$ in the S_ECC specimens cured under CW were healed with significant amount of calcium carbonate (Fig. 8c).

To complement the microscopy results, XRD analysis was also performed. A small amount of healing materials scratched from 


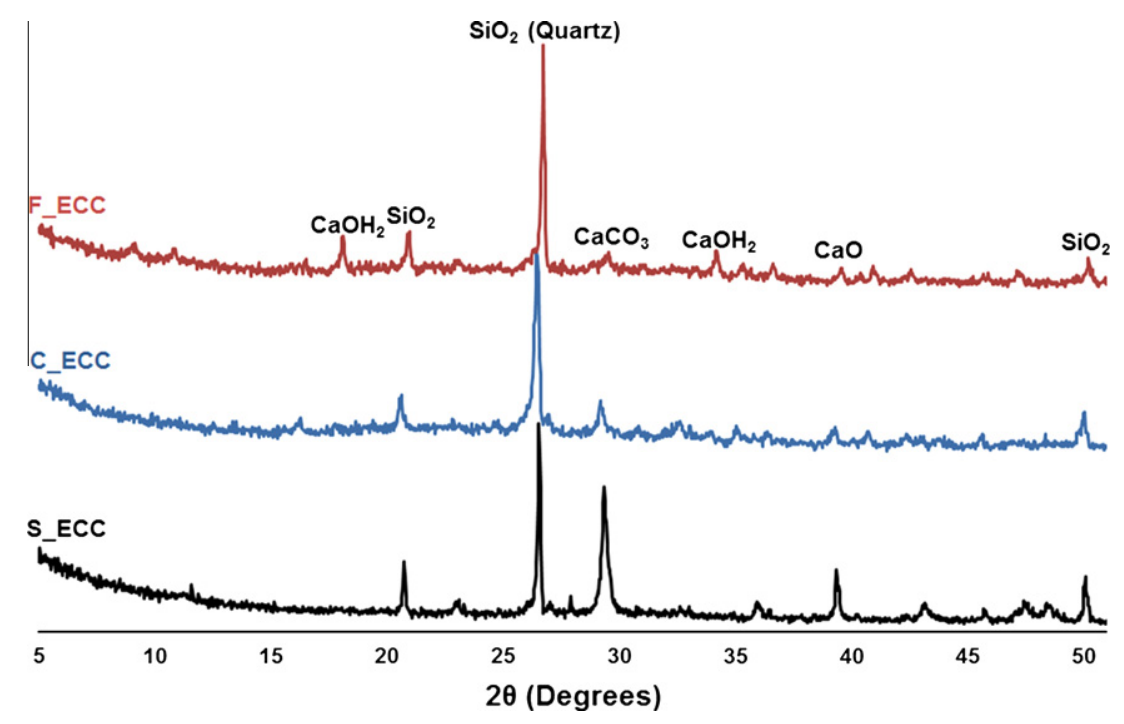

Fig. 9. XRD patterns of self-healing products in ECC mixtures.

the precracked ECC samples was observed by XRD. X-ray diffractograms of ECC mixtures involved in this study (Fig. 9) show well-defined peaks. The diffractogram of pre-loaded FA-ECC specimen that underwent healing contained quartz (from fly ash and/or silica sand) and some calcite. The diffractogram of samples taken from pre-loaded C_ECC (Fig. 9) appears similar to that of F_ECC (Fig. 9), though the peaks related to calcite are slightly better defined (Fig. 9). Although some quartz is still evident from diffractogram obtained from pre-loaded S_ECC specimens, the majority of peaks are related to calcite (Fig. 9). Overall, these results indicate that calcite is the primary crystalline product involved in the healing process of S_ECC. To facilitate healing of the cracks and promote formation of calcium carbonate, $\mathrm{Ca}^{2+}$ from hydration products must leach out of the hardened matrix into cracks and react with carbon dioxide. Without the presence of water, this leaching process is not possible. Carbon dioxide in gaseous form only reacts with $\mathrm{CH}$ in sufficiently high relative humidity and over long time periods [31]. Water or water curing also provide a much higher concentration of carbon dioxide, both as a dissolved gas and as a bicarbonate solution, than that of the laboratory air curing, where the amount of carbon dioxide is limited [32]. Continued hydration of unhydrated cement particles is also faster in water. Because of mentioned considerations, preloaded specimens, which were further cured under CW had healed itself better than those of exposed to further CA curing.

The fast and high self-healing capability of pre-cracked S_ECC specimens might be correlated with the high $\mathrm{pH}$ value of pore solution. It is well-known that $\mathrm{C}-\mathrm{S}-\mathrm{H}$ gels together with $\mathrm{CH}$ and alkalis $\left(\mathrm{Na}_{2} \mathrm{O}\right.$ and $\left.\mathrm{K}_{2} \mathrm{O}\right)$ present in the system dominate the chemical properties of aqueous phase in the cement paste and are responsible for high $\mathrm{pH}$ value of pore solution. Initially, with the dissolution of alkalis, $\mathrm{pH}$ value of more than 12 in the pore solution is easy to attain [33]. However, this hyper-alkaline stage is not long-lasting and with the further consumption of hydroxides in time, $\mathrm{pH}$ value is expected to decrease. The consumption of hydroxides which is associated with the pozzolanic capacity of SCMs is more understandable by controlling the main ingredients tabulated in Table 2. As it is seen from Table 2, amount of $\mathrm{SiO}_{2}$ which is one of the main ingredients responsible for the pozzolanic activity is higher for FAs compared to slag. The amount of $\mathrm{CaO}$ that is mainly responsible for the cementing behavior, however, is higher for slag compared to FAs. Decrease in $\mathrm{pH}$ value which has a close relationship with the dissolution of carbonate species, precipitation of calcite crystals and final self-healing behavior in late age can be associated with the high amounts of $\mathrm{SiO}_{2}$ that would lead to consumption of further $\mathrm{CH}$ in the case of C_ECC and F_ECC specimens [9]. Since, the amount of $\mathrm{CH}$ is expected to be high for S_ECC specimens due to low levels of $\mathrm{SiO}_{2}$ amount in slag, it is likely to say that $\mathrm{pH}$ value were kept higher even at the late ages leading to higher rates of $\mathrm{CaCO}_{3}$ precipitation [9], which in turn triggers high levels of selfhealing. Further investigations must be made to understand the rate of carbonation that would lead to significant amount of selfhealing in the case of cementititous composites.

\section{Conclusions}

The self-healing behavior of a series of pre-cracked ECC specimens incorporating different SCMs is investigated in this paper, focusing on the recovery of its chloride ion permeation properties. Three SCMs (Class-C and Class-F fly ashes and slag), selected to represent the wide range of composition of SCMs, were used in the study. To generate microcracks, the splitting tensile preloading deformation levels were chosen as $1.00 \mathrm{~mm}, 1.25 \mathrm{~mm}$ and up to failure. The pre-determined deformation levels were introduced to ECC mixtures at the age of 60 days, and specimens were further exposed to continuous wet (CW), continuous air (CA) and cyclic F/T curing conditions up to $60+60$ days. In order to observe the effects of different SCMs on the self-healing capability of ECC mixtures, RCPT and detailed microstructural analysis were conducted at the pre-specified days. From the results obtained, the following conclusions can be drawn:

1. Different from the water penetration properties of microcracked ECC specimens [27], the applied splitting tensile preloading affected the chloride ion penetration of the ECC specimens. In particular, for the highly preloaded ECC specimens, the measured chloride ion permeability rate was very high. Compared to the FA-ECC specimens, the increase was low for the S_ECC specimens; and even for specimens loaded up to failure, S_ECC specimens exhibited high resistance to chloride ion penetration.

2. Except for the specimens exposed to F/T cycle, RCPT results for all ECC specimens decreased as curing time extended showing that significant amount of self-healing is attained. The effect of CW curing is more pronounced on the chloride ion permeability results especially for the preloaded specimens, emphasizing the importance of water for further hydration and selfhealing. 
3. At the end of $300 \mathrm{~F} / \mathrm{T}$ cycles, all FA-ECC specimens showed an increase in RCPT values, regardless of preloading deformation level. The increase in chloride permeability results was more pronounced for the pre-loaded specimens. Moreover, compared to Class-C FA, the use of Class-F FA can further exacerbate the deterioration caused by $\mathrm{F} / \mathrm{T}$ cycles. On the other hand, no increases in RCPT values were observed on both pristine and preloaded S_ECC specimens even after 300 cycles of F/T. This was probably due to the greater maturity of the slag-ECC test specimens.

4. The microscopic observation of the pre-loaded ECC specimens showed that self-healing was attained up to certain limits, regardless of the mixture type. However, the main restriction for an absolute self-healing to occur was correlated back to the permissible crack widths. It was roughly found that F_ECC specimens could heal the cracks with the width of $30 \mu \mathrm{m}$. This value was around $50 \mu \mathrm{m}$ for C_ECC and slightly above $100 \mu \mathrm{m}$ for S_ECC specimens. Microstructural analysis also indicated that the main self-healing products are calcite and $\mathrm{C}-\mathrm{S}-\mathrm{H}$ gels, varying by SCM types used in ECC production. $\mathrm{C}-\mathrm{S}-\mathrm{H}$ and calcite are the main self-healing product for FA-ECC mixtures, and calcite is the main self-healing product for the S_ECC mixture. The reason behind the significant amount of self-healing attainment of S_ECC specimens may be associated with the higher $\mathrm{pH}$ value of the pore solution and $\mathrm{CaO}$ content of slag that would favor the precipitation of calcite.

It is important to note that many of the findings mentioned above for ECC can also be applicable to other fiber reinforced cement-based composites that achieve tight and distributed cracking at high levels of deformation.

\section{Acknowledgements}

The authors gratefully acknowledge the financial assistance of the Scientific and Technical Research Council (TUBITAK) of Turkey provided under Project: MAG-108M495 and Gaziantep University Scientific Research Centre provided under Project: MF.10.09.

\section{References}

[1] Mehta PK, Gerwick BC. Cracking-corrosion interaction in concrete exposed to marine environment. Concr Int 1982;4:45-51.

[2] Li VC. Engineered cementitious composites tailored composites through micromechanical modeling. In: Banthia N, Bentur A, Mufti A, editors. Fiber reinforced concrete: present and the future, Canadian Society for Civil Engineering; 1997. p. 64-97.

[3] Li VC. On engineered cementitious composites (ECCs): a review of the material and its applications. J Adv Concr Technol 2003;1:215-30.

[4] Lin Z, Li VC. Crack bridging in fiber reinforced cementitious composites with slip-hardening interfaces. J Mech Phys Solid 1997;45:763-87.

[5] Lin Z, Kanda T, Li VC. On interface property characterization and performance of fiber reinforced cementitious composites. Concr Sci Eng 1999;1:173-84.
[6] Jacobsen S, Marchand J, Homain H. SEM observations of the microstructure of frost deteriorated and self-healed concrete. J Cem Concr Res 1995;25:1781-90.

[7] Reinhardt H, Joos M. Permeability and self-healing of cracked concrete as a function of temperature and crack width. J Cem Concr Res 2003;33:981-5.

[8] Şahmaran M, Yaman IO. Influence of transverse crack width on reinforcement corrosion initiation and propagation in mortar beams. Can J Civil Eng 2008;35:236-45.

[9] Edvardsen C. Water permeability and autogenous healing of cracks in concrete. ACI Mater J 1999;96:448-55.

[10] Aldea C, Song W, Popovics JS, Shah SP. Extent of healing of cracked normal strength concrete. J Mater Civil Eng 2000;12:92-6.

[11] Clear CA. The effects of autogenous healing upon the leakage of water through cracks in concrete. Wexham Springs: Cement and Concrete Association; 1985. p. 28.

[12] Şahmaran M, Li VC. De-icing salt scaling resistance of mechanically loaded engineered cementitious composites. J Cem Concr Res 2007;37:1035-46.

[13] Wang S, Li VC. Engineered cementitious composites with high-volume fly ash. ACI Mater J 2007; 104:233-41.

[14] Qian S, Zhou J, de Rooij MR, Schlangen E, Ye G, van Breugel K. Self-healing behavior of strain hardening cementitious composites incorporating local waste materials. J Cem Concr Compos 2009;31:613-21.

[15] ASTM C1202. Electrical indication of concrete's ability to resist chloride ion penetration. Annual book of ASTM standards, Philadelphia, PA; 1997.

[16] Li VC, Wang S, Wu C. Tensile strain-hardening behavior of PVA-ECC. ACI Mater J 2001;98:483-92.

[17] Shi C. Effect of mixing proportions of concrete on its electrical conductivity and the rapid chloride permeability test (ASTM C1202 or ASSHTO T277) results. J Cem Concr Res 2004;34:537-45.

[18] Misra S, Yamamoto A, Tsutsumi T. Application of rapid chloride permeability test to qualify control of concrete. In: Malhotra VM, editor. Proceedings of concrete durability 3rd international conference; 1994. p. 487-502.

[19] ASTM C666-97. Standard test method for resistance of concrete to rapid freezing and thawing. Annual book of ASTM standards, West Conshohocken, PA; 1997.

[20] ASTM C39-05. Standard test method for compressive strength of cylindrical concrete specimens. Annual book of ASTM standards, West Conshohocken, PA; 2005.

[21] Li G, Zhao X. Properties of concrete incorporating fly ash and ground granulated blast-furnace slag. J Cem Concr Compos 2003;25:293-9.

[22] Qian S, Li VC. Simplified inverse method for determining the tensile properties of strain hardening cementitious composites. J Adv Concr Technol 2008;6:353-63.

[23] Mehta PK, Monteiro PJM. Concrete: microstructure, properties and material. 3rd ed. McGraw Hill; 2006.

[24] Şahmaran M, Yaman IÖ, Tokyay M. Development of high volume low-lime and high-lime fly-ash-incorporated self consolidating concrete. Mag Concr Res 2007; 59:97-106.

[25] Şahmaran M, Li VC. Durability properties of micro-cracked ECC containing high volumes fly ash. J Cem Concr Res 2009;39:1033-43.

[26] Song G, van Zijl GPAG. Tailoring ECC for commercial application. In: di Prisco M, Felicetti R, Plizzari GA, editors. Sixth international RILEM symposium on fiber reinforced concrete, RILEM Pro039; 2004. p. 1391-400.

[27] Lepech M, Li VC. Water permeability of cracked cementitious composites. In: Proceedings of 11th international conference on fracture, Turin, Italy; 2005. p. $20-5$.

[28] Mindess S, Young JF, Darwin D. Concrete. 2nd ed. Prentice Hall; 2002.

[29] Joos M. Leaching of concrete under thermal influence. Otto-Graf-J 2001;12:51-68.

[30] Sun W, Zhang YM, Yan HD, Mu R. Damage and damage resistance of high strength concrete under the action of load and freeze-thaw cycles. J Cem Concr Res 1999;29:1519-23.

[31] Neville A. Autogenous healing - a concrete miracle? Concr Int 2002;24:76-82.

[32] Kenneth RL, Floyd OS. Autogenous healing of cement paste. J ACI 1956;27:1083-97.

[33] Anstice D, Page C, Page M. The pore solution phase of carbonated cement pastes. J Cem Concr Res 2005;35:377-83. 